\title{
Examining Student and Teacher Talk Within Engineering Design in Kindergarten
}

\author{
Kristina M. Tank ${ }^{1 *}$, Anastasia M. Rynearson ${ }^{2}$, Tamara J. Moore ${ }^{3}$ \\ ${ }^{1}$ Iowa State University, 0624C Lagomarcino, 901 Stange Rd, 50011 Ames, USA \\ ${ }^{2}$ Campbell University, USA \\ ${ }^{3}$ Purdue University, USA
}

*Corresponding Author: kmtank@iastate.edu

Citation: Tank, K. M., Rynearson, A. M. and Moore, T. J. (2018). Examining Student and Teacher Talk Within Engineering Design in Kindergarten. European Journal of STEM Education, 3(3), 10. https://doi.org/10.20897/ ejsteme/3870

Published: September 6, 2018

\begin{abstract}
Quality science, technology, engineering, and mathematics (STEM) experiences during the early years provide young learners with a critical foundation for future learning and development. Engineering design is a context that can be used to facilitate connections and learning across STEM, however there is limited research examining the use of engineering design-based STEM integration within the early childhood classroom. This study examines how an engineering design-based STEM integration unit was enacted across three kindergarten classrooms. Classroom observation and video data were collected and a coding scheme was used to document the ways that engineering and engineering design were enacted as well as the role of the teacher and students within the lessons. Results suggest that kindergarten students were able to meaningfully engage in and with multiple stages of an engineering design process while also building understanding of scientists and engineers related to teacher and student interactions, there were multiple instances of student-initiated talk, student to student response, the use of explicit engineering language and of students making connections to prior learning. This suggests that the enactment of engineering design in early childhood should incorporate multiple aspects of engineering and engineering design, include interdisciplinary content and provide a context for STEM integration.
\end{abstract}

Keywords: early childhood, engineering design, STEM integration

\section{INTRODUCTION}

Within STEM education, there remains a call for the use of a more integrated approach to STEM that allows educators and researchers to cross disciplinary boundaries and engage students in more integrated and interdisciplinary thinking and experiences (e.g. English, 2016; NRC, 2012; 2014). This focus on a more interdisciplinary approach to teaching and STEM has not only been found to increase student learning and motivation (Brophy et al., 2008) but also lays an important foundation for future learning (Kuhn and Pearsall, 2000). Furthermore, an integrated and interdisciplinary approach aligns with developmentally appropriate practice in early childhood that recommends that "teachers plan curriculum experiences that integrate children's learning with and across... disciplines" (Copple and Bredekamp, 2009, p.21). Within these early integrated STEM experiences, the interdisciplinary nature of engineering provides a link across STEM disciplines and is an ideal vehicle for advancing the natural curiosity and problem-solving skills that characterize early childhood classrooms (Tank et al., 2018; Brophy et al., 2008). However, there is limited research within the areas of early childhood 
STEM and engineering (English, 2015; Lippard et al., 2017), and as these areas continue to grow there is a need for more research examining integrated STEM with a special attention to engineering, and the ways and types of engineering experiences and interactions that can be highlighted within an early childhood classroom.

Recommendations from emerging research in the area of early childhood engineering and STEM suggests that engineering experiences at this level should include a focus on engineering design as that provides opportunities and contexts for learning about and applying science \& mathematics content (Tank et al., 2018; Wendell and Rodgers, 2013), engages students in real-world problem situations (Brophy et al., 2008; Cunningham and Lachapelle, 2014) and capitalizes on young learners' natural curiosity to solve problems and see how things work (Bairaktarova et al., 2011). While design is a key component of engineering, it is also important to present experiences that help to show that engineering is more than just design (Moore et al., 2014) as these experiences can provide opportunities to develop engineering thinking skills (Brophy and Evangelou, 2007; Adams et al., 2011; Lippard et al., 2017) and an understanding of engineers, engineering and the problems that engineers face (Adams et al., 2011; Lachapelle and Cunningham, 2014; Watkins et al., 2014). Furthermore, when thinking about the translation of engineering into the early elementary classroom, Evangelou in Adams et al. (2011) notes the importance of setting up experiences that assist learners in self-initiated, but adult-supported learning. This focus on the importance of providing carefully planned experiences that promote interactions with adults as facilitators and supporters of their learning was also echoed in the systematic literature review by Lippard et al., 2017.

Although this emerging body of research around early childhood engineering and STEM presents recommendations for early engineering, the field is still working to understand how these recommendations are translated into practice in real classrooms and the types of engineering experiences that can be successfully integrated into an already tightly-packed curriculum. Within this study, we were interested in learning more about how engineering is enacted in an early elementary classroom. To do this, we conducted an exploratory, descriptive research study in which we wanted to know, within the context of an integrated STEM unit that emphasizes engineering design, what does engineering look like in a Kindergarten classroom? More specifically we were looking to better understand the role of teacher and student talk within this context, what types of interactions around engineering were occurring in the classroom and if these interactions were student or teacher-initiated.

\section{METHODS}

This study employed a naturalistic inquiry approach (Lincoln and Guba, 1985) in which the goal is to observe, describe, and interpret the actions and experiences of people within their natural setting. Meaning arises out of social situations and therefore the context of the kindergarten classrooms and the events and interactions that occurred within these classrooms were an important part of the research setting. This type of approach is valuable for exploratory and descriptive research in which little is known about the people or social context that is being investigated, as is the case for early childhood engineering which is a newly emerging field.

\section{Conceptual Framework}

Engineering design-based STEM integration was the conceptual framework that guided this study. Engineering design-based STEM integration is defined as the use of learning objectives that are composed of engineering design and at least one of the other STEM disciplines within the same classroom activity, unit, or learning experience for students. The engineering design challenge in the STEM integration learning experiences acts as the integrator for all of the other subjects (Moore, Stohlmann et al., 2014; Grubbs and Strimel, 2015). The Grand Challenges for Engineering (National Academy of Engineering, 2008) are the greatest engineering challenges facing our planet. These challenges epitomize the interdisciplinary nature of engineering problems, particularly the problems that are facing engineers of the 21st century. To meet these problems, today's students must become engineers who can meet these challenges. To prepare today's students to meet the problems of tomorrow, opportunities to engage with authentic, real-world, and interdisciplinary problems and ideas must be available to spark interest in STEM fields. Powerful, engaging experiences within rich, integrated STEM contexts must be provided to engage, interest, and support students as they prepare to meet the problems of our increasingly technological society. The core of engineering practice is often considered to be engineering design, a way of thinking and engaging with problems to meet the needs of society. This purposeful thinking, or engineering design, is the "distinguishing mark of the engineering profession" (Dym, 1999). When state standards incorporate engineering, they commonly incorporate engineering design as part of their science or standalone engineering standards (Moore et al., 2015). Engineering design is also incorporated into the Next Generation Science Standards alongside engineering habits of mind and an acknowledgement of the intersection of engineering within science education standards. From these standards, however, there is little guidance or structure for engineering integration, and this need is not yet met by policy makers or researchers across the P-12 education landscape. In relation to this study and engineering design-based 
Table 1. Designing Paper Baskets curriculum unit summary

\begin{tabular}{lll}
\hline Lesson & Literacy Lesson Focus & STEM Lesson Focus \\
\hline 1: Paper & $\begin{array}{l}\text { While reading If You Find a Rock by Peggy Christian, students } \\
\text { work on identifying beginning and ending sounds of words }\end{array}$ & $\begin{array}{l}\text { Identify the properties of the paper samples and sort } \\
\text { using those properties. }\end{array}$ \\
\hline $\begin{array}{l}\text { 2: Paper and } \\
\text { Water }\end{array}$ & $\begin{array}{l}\text { The first part of I Get Wet by Vikki Cobb introduces students } \\
\text { to water while allowing students to blend three letters in } \\
\text { sound boxes that represent the phonemes of a word }\end{array}$ & $\begin{array}{l}\text { Learn about properties of paper when wet and dry } \\
\text { through the water drop test, wax and water test. }\end{array}$ \\
\hline 3: Paper Strength & $\begin{array}{l}\text { The second part of I Get Wet by Vikki Cobb provides } \\
\text { background science knowledge as students work to } \\
\text { summarize text using interactive writing }\end{array}$ & Test the strength of dry/wet paper with rocks. \\
\hline $\begin{array}{l}\text { 4: Patterns and } \\
\text { Your Design }\end{array}$ & $\begin{array}{l}\text { In Pattern Fish by Trudy Harris students practice their } \\
\text { patterning while also being introduced to rhyming words }\end{array}$ & $\begin{array}{l}\text { Identify and create patterns, explore the patterns that } \\
\text { can be used as they identify a weaving pattern for } \\
\text { basket plan. }\end{array}$ \\
\hline $\begin{array}{l}\text { 5: Testing your } \\
\text { Basket }\end{array}$ & $\begin{array}{l}\text { Rocks, Jeans and Busy Machines by Alane \& Raymundo Rivera } \\
\text { leads a lesson on summarizing narrative text with interactive } \\
\text { sentence writing }\end{array}$ & $\begin{array}{l}\text { Engage students in the second part of the engineering } \\
\text { design process as they test baskets with wet and dry } \\
\text { rocks and communicate solution to clients. }\end{array}$ \\
\hline
\end{tabular}

STEM integration, the learning objectives for the entire unit came from all four STEM disciplines, but each lesson focused on engineering design and at least one other content area.

\section{Participants and Context}

This research is part of a larger project that is examining engineering design and computational thinking within integrated STEM experiences for K-2 students. As part of this larger project, the three teachers agreed to implement the same integrated STEM curricular unit, Designing Paper Baskets (described below) that was developed by the research team (Tank et al., 2018). This particular study was focused on examining the implementation of this curriculum in three kindergarten classrooms and specifically looking at student and teacher talk and the types of interactions around engineering that were occurring and who was initiating these interactions. The data for this project were collected from all three full-day Kindergarten classrooms at a K-8 public charter school located in a small city in a Midwestern state within the United States that includes 57\% students on free-reduced lunch (lower socio-economic status) and 22\% students of color (not identified as 100\% Caucasian). Each of the Kindergarten classrooms were taught by one of three Caucasian, female teachers who were within their first five years of teaching and representative of early elementary teachers in that they had not received specific coursework or training related to integrated STEM. Additionally, these teachers only received a one-hour, on-site introduction to the curriculum as they implemented this curricular unit prior to any participation in professional development around engineering and integrated STEM. This allowed for the researchers to gather data that was somewhat representative of the typical early elementary classrooms where teachers do not have access to specific STEM professional development prior to implementation (Banilower et al., 2013). While the choice of where and from whom to collect data was meant to be somewhat representative of Kindergarten classrooms, these data are specific to this school and these three classrooms, teachers, and students; therefore, while the lessons we learned from this study are likely to be true elsewhere, caution should be taken when making such generalizations. Data were collected from 32 students across the three classrooms in accordance with IRB \#1401014380.

\section{Curriculum as the Research Setting}

The integrated STEM curriculum unit, Designing Paper Baskets that was implemented in all three of the Kindergarten classrooms is part of the PictureSTEM curriculum project that uses picture books, an engineering design challenge, and student-centered pedagogies to provide authentic, contextual activities that engage learners in specific science, technology, engineering, and mathematics content. There are four primary components that serve as a foundation for this curriculum: 1) engineering design as the interdisciplinary glue that is present throughout the integrated STEM unit, 2) realistic engineering contexts to promote student engagement, 3) highquality literature to facilitate meaningful connections and 4) instruction of standards-based STEM content using student-centered pedagogies, with a particular focus on evidence-based reasoning as a means to tie the subjects together (Tank et al., 2018). The implementation of this engineering design-based STEM integration curriculum is the context for observing evidence of engineering experiences, talk, and interactions that occur within these three Kindergarten classrooms. Since the focus of this study was to explore what engineering looks like in practice within an actual classroom, asking the teachers to all use the same integrated STEM curriculum was an attempt at providing a consistent curriculum and instructional approach across the classrooms.

The particular curriculum unit, Designing Paper Baskets, that was implemented in this study focuses on the development of the mathematics concept of pattern recognition and the science concept of exploring physical properties and materials. In addition to the five lessons shown in Table 1, there is an introductory lesson where engineering, specifically the engineering design process, and the overarching engineering design challenge is introduced to students. The engineering design challenge for this unit, asks students to assist two fellow 


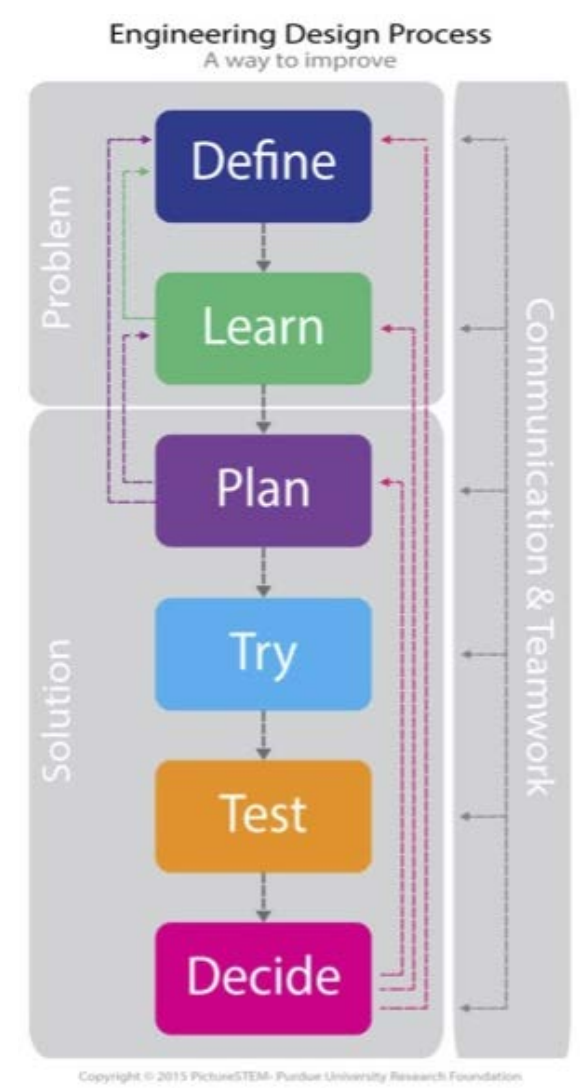

Figure 1. Engineering Design Process

kindergarteners, Max and Lola, in creating a design for a paper basket that can be used to transport wet and dry rocks for other children interested in starting a rock collection.

\section{Data Collection \& Analysis}

The video data were collected using three cameras on tripods during the PictureSTEM curriculum lessons, one per classroom. When a member of the research team was available, they would set up the camera and take field notes during the lesson. When no researcher was available, the teachers themselves set up the tripod in a reasonable location for the duration of the lesson. Video data was collected for all five literacy and STEM lessons for each of the three teachers. Videos were analyzed using the Dedoose qualitative analysis software (www.dedoose.com) and uploaded to the secure Dedoose platform for researchers to access the videos for asynchronous coding. For each of the individual lessons that make up the larger curriculum unit researchers watched each of the classroom videos and identified excerpts, or small clips, within the videos that were focused on activities or interactions related to engineering. In this study, an excerpt is defined as the full interaction rather than by a specific time. This allowed for a condensing and categorizing of the data around the research question of examining what engineering looks like in a Kindergarten classroom. These excerpts became the unit of analysis and the focus of the coding and analysis for this study.

Initially, all researchers reviewed a selected subset of the video data (Derry et al., 2010) Using the engineering design process, presented in Figure 1, as a provisional analytic framework, researchers deductively and inductively created a coding scheme to analyze the video data (Miles et al., 2014). This version of the engineering design process was developed through multiple research and curriculum studies (e.g., see Moore and Tank, 2014; Tank et al., 2016; Tank et al., 2018). The first of these studies, the Framework for Quality Engineering Education (Moore et al., 2014), defined the engineering design process as the following six phases: problem, background, plan, implement, test, and evaluate. Through our research and curriculum development with young children, we found that these terms were difficult for the young students to understand. Therefore, we changed the language to be more accessible by making "problem" into "define the problem", "background" into "learn about the problem", "plan" into "plan a solution", "implement" into "try your plan", "test" into "test your solution", and "evaluate" into "decide if your solution is good enough." Throughout this manuscript, we will shorten these definitions into the just the colored words shown in Figure 1. These phases as defined in Moore et al. (2014) with the new names from Tank et al. (2018) were used to guide the first round of coding.

Further analysis of the data and iterative cycles of coding allowed for the emergence of additional codes and sub codes that related to the research questions but were not captured in the provisional framework (Miles et al., 
2014), such as connections to curriculum, student talk and teacher talk. The resulting coding scheme was used to document the ways that engineering and engineering design, were framed and enacted in the classroom as well as the role that the teacher and students played within the lessons. The set of codes, sub-codes, and an example of each that made up the final coding scheme are divided by category and presented in Table 2 .

Table 2. Final coding scheme and representative examples

\section{Codes Key terms or actions Example(s)}

\begin{tabular}{ll} 
Engineering & Design Process \\
\hline Define & $\begin{array}{l}\text { Criteria, Constraint, Client, End-user } \\
\text { Problem }\end{array}$
\end{tabular}

\section{Now who are we helping? \\ Max!}

Max and Lola, right, we're helping Max and Lola. C1, LO

We're going to design a basket, we want it to?

Look pretty! C1, L5B

Well, what was the letter about?

Rocks!

Yeah, what do we need to do?

Make a rock activity! C3, LO

\begin{tabular}{|c|c|c|}
\hline Learn & $\begin{array}{l}\text { Science, Math, Materials exploration, } \\
\text { Other solutions, Defining specs (trade- } \\
\text { offs, criteria, constraints, end-user, } \\
\text { client), Past Experiences }\end{array}$ & $\begin{array}{l}\text { Okay, so we're going to read this book called Pattern Fish to help us learn about } \\
\text { patterns. C1, } L A A \\
\text { I'm curious, what happened with the tissue paper? } \\
\text { The tissue paper? Our tissue paper \{lifts it up\} } \\
\text { Had a hole in it? } \\
\text { Yeah. C2, L3B }\end{array}$ \\
\hline Plan & $\begin{array}{l}\text { Brainstorm solutions, Consider } \\
\text { constraints \& trade- offs, Choice of } \\
\text { plan, Develop physical plan, } \\
\text { Defining/Modifying Specifications }\end{array}$ & $\begin{array}{l}\text { I am going to partner you up and then you are going to talk. You are going to tell } \\
\text { me what you and your partner decided to do, why you chose the papers, and how } \\
\text { it's going to meet Max and Lola's needs. It has to look pretty and has to hold wet } \\
\text { and dry rocks, right? C3, L4B } \\
\text { I know which type of paper to use! } \\
\text { Well, what kind of paper do you think? } \\
\text { It's the first paper we tried! Wax...it holds wet and dry! C2, L3A }\end{array}$ \\
\hline Try & $\begin{array}{l}\text { Consider Risk, Create prototype, } \\
\text { Trade-offs }\end{array}$ & $\begin{array}{l}\text { Done! } \\
\text { You guys used the over under pattern, right? } \\
\text { Over-under, over-under. } \\
\text { Yeah, you did, good job! } C 3, L A B \\
\text { Now what you guys have to do is fold it in half and tape the sides. } \\
\text { Okay this is ours! } C 1, L 4 B\end{array}$ \\
\hline Test & $\begin{array}{l}\text { Collect \& Analyze Data, } \\
\text { Defining/Modifying Specifications } \\
\text { Failure }\end{array}$ & $\begin{array}{l}\text { Three...four...five... Ours broke! } C 3, L 5 B \\
\ldots \text {.nineteen, twenty, twenty-one }\{\text { basket breaks }\} \\
\text { Oh! } \\
\text { Twenty rocks. } C 1, L 5 B\end{array}$ \\
\hline Decide & $\begin{array}{l}\text { Share results, Failure, Criteria, } \\
\text { Constraints, Improve, Redesign }\end{array}$ & $\begin{array}{l}\text { We didn't have more weaving so there's a hole but it didn't break. I think it will } \\
\text { have more weaving. C3, } L 5 B\end{array}$ \\
\hline \multicolumn{3}{|c|}{ Interaction Type } \\
\hline $\begin{array}{l}\text { Teacher- } \\
\text { focused }\end{array}$ & $\begin{array}{l}\text { Teacher talk, action, response, teacher } \\
\text { initiated, provides knowledge }\end{array}$ & $\begin{array}{l}\text { We're going to read this book If You Find a Rock and we're going to read about it } \\
\text { because this is Learning about some of the things that we need for our engineering } \\
\text { process, we're going to learn some about rocks. C1, L1A } \\
\text { I already see some people who are thinking in their head about what's happening } \\
\text { and thinking about what they're going to do differently next time. C1, L5B }\end{array}$ \\
\hline $\begin{array}{l}\text { Student- } \\
\text { focused }\end{array}$ & $\begin{array}{l}\text { Student talk, action, response, student } \\
\text { providing knowledge }\end{array}$ & $\begin{array}{l}\text { Now we're done with papers. We're done with testing. } C 1, L 4 B \\
\text { So what did you make it out of? } \\
\text { Construction paper! } C 1, L 5 B \\
\text { My basket looks almost done! } \\
\text { No, our basket. } \\
\text { My basket. } \\
\text { Your basket looks fantastic! } \\
\text { No our basket. C3, L4B }\end{array}$ \\
\hline
\end{tabular}

\section{Other Areas of Interest}

\begin{tabular}{|c|c|c|}
\hline $\begin{array}{l}\text { Connections } \\
\text { to Curricula }\end{array}$ & $\begin{array}{l}\text { Refers back to engineering design } \\
\text { process, Book (literacy), Math } \\
\text { lesson/content, Science lesson/content }\end{array}$ & $\begin{array}{l}\text { Let's think back to when we read If You Find } A \text { Rock and who can remember what } \\
\text { kind of rock was in the story that you like, what was your favorite? } C 1, L 1 B \\
\text { Now in the book Pattern Fish, they talked about "yellow black, yellow black, yellow } \\
\text { black" is an AB pattern, right? C2, LAB }\end{array}$ \\
\hline $\begin{array}{l}\text { Explicit } \\
\text { Engineering } \\
\text { Language }\end{array}$ & & We're moving down to Plan, we get to Plan the design of our baskets $C 1, L A B$ \\
\hline $\begin{array}{l}\text { Conceptions } \\
\text { of Engineers } \\
\text { and } \\
\text { Engineering }\end{array}$ & $\begin{array}{l}\text { Identifying what engineers do, } \\
\text { identifying self or others as engineers }\end{array}$ & $\begin{array}{l}\text { We're gonna be like a scientist! } \\
\text { We are, we're going to be like engineers. } C 1, L 3 B\end{array}$ \\
\hline
\end{tabular}


All four coders for this project were already familiar with the initial codes and their definitions from prior research that had been conducted. Prior to coding all of the data, the four coders rated common video clips to assure that our coding was calibrated. After coding the clips, we used Randolph's free marginal kappa to calculate the interrater reliability (IRR) for the four coders. Randolph's free marginal kappa is a variant of Fleiss' kappa (Fleiss, 1971), which is the most common replacement for Cohen's kappa when there are more than 2 raters. We chose to use Randolph's free marginal kappa to also take into account that there were not specified numbers of each category that must be coded. Our IRR for this study was multi-rater $\boldsymbol{\kappa}_{\text {free }}=0.941$, which is almost perfect agreement according to Landis and Koch (1977).

Following the establishment of interrater reliability with the coding scheme, the research team divided the data to analyze and coded individually. The codes represent instances of engineering related actions, interactions and conversations that were seen throughout the enactment of the lesson. This allowed for the categorization and identification of reoccurring patterns within the data based on the clustering of similar codes, which led to a smaller number of patterns codes that could be grouped into larger themes (Miles et al., 2014). Through this process of coding, organizing, and clustering the data, several themes emerged related to the bigger categories of engineering design, talk and interactions as well as several unexpected themes that will be presented in the subsequent section.

\section{RESULTS}

When looking at the results of the coding and analysis, there were several themes that emerged related to the larger research question examining what engineering looks like in a kindergarten classroom by looking at the talk and types of interactions that were occurring during instruction. Across the three classrooms students, with the support of the teacher, were seen to engage in and with all of the stages of an engineering design process with an emphasis on the learn stage where they were building knowledge of the problem and content. Additionally, there was evidence that as students were participating in these engineering design-based STEM experiences that they were also building their understanding of scientists and engineers, as well as some early self-conceptions of being scientists and engineers. Finally, when looking at the role of the teacher and students within this context, even though there was a lot of teacher talk throughout the lessons, there was also evidence of a large number of unprompted student talk, student to student response, the use of explicit engineering language and student connections to prior learning and experiences seen across the curriculum. Additional description and examples around each of these larger themes will be discussed in the following sections. Excerpts are noted by classroom and lesson; for example, C1, L3B would be an excerpt from Classroom 1 during Lesson 3B. See Table 1 for lesson descriptions.

\section{Overview}

Using the internal analysis available in Dedoose (version 7.5.9), a word cloud portraying the relative number of each code applied during the coding analysis is shown in Figure 2. This word cloud provides a picture of the patterns that were seen as this engineering design-based STEM unit was enacted in the three kindergarten classrooms. When looking across the stages of the engineering design process, the unit focused heavily on the Learn stage with 218 total coded excerpts identified for that stage. This is expected as STEM lessons $1-3$ and all Literacy lessons have been designed to help students to build background knowledge around the problem and content necessary for solving the engineering design challenge and therefore would be in the Learn stage. Learning specifically about the materials that would be used to weave their baskets and the strength and how the materials interacted with water was found to be the largest single aspect of the lessons with 145 coded excerpts. 


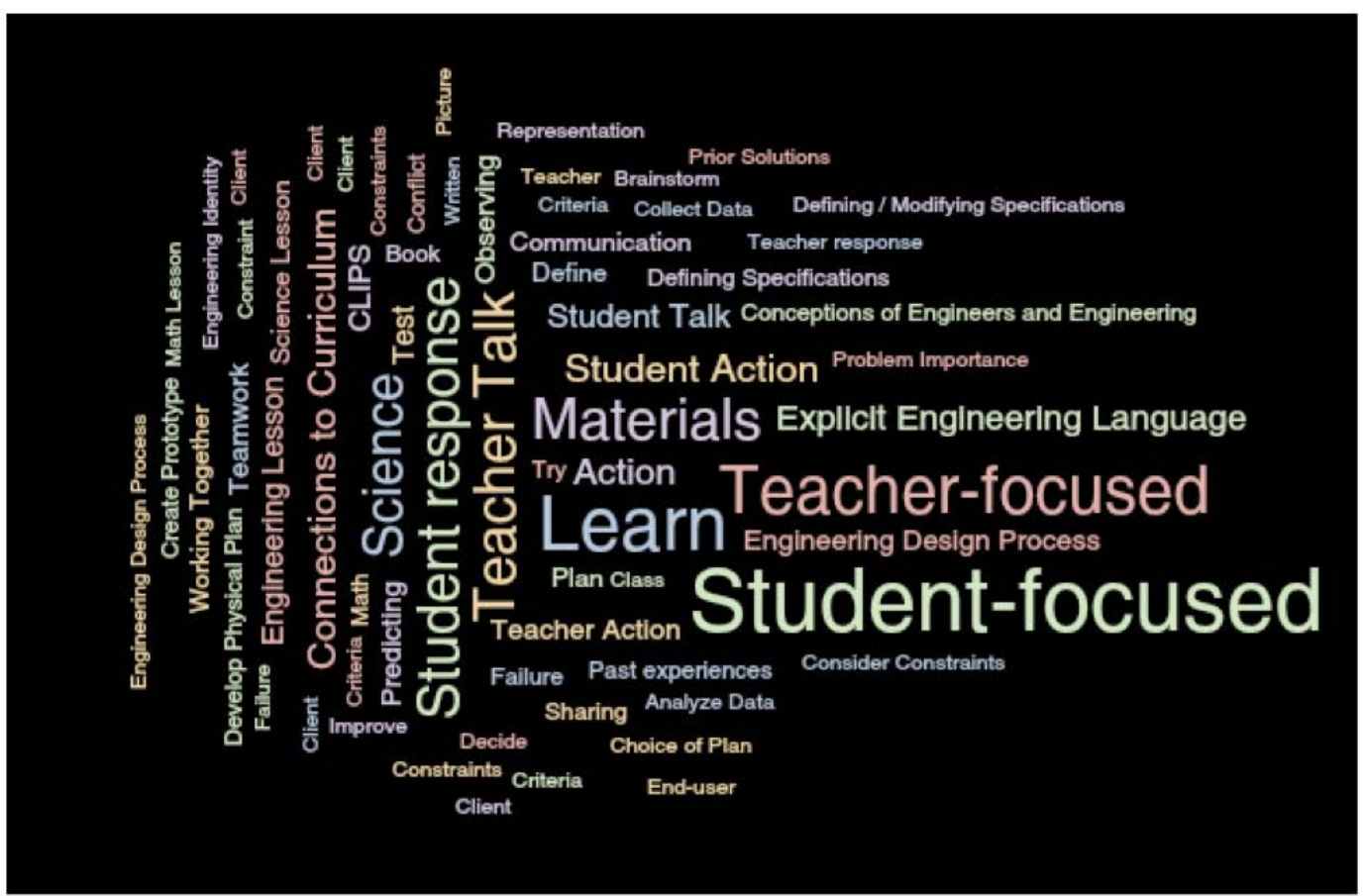

Figure 2. Word cloud indicating number of times each code was used in relation to all codes

Another interesting pattern that emerged, that was related to the student-teacher interactions around engineering, and revealed that there were more student-focused excerpts, 265, compared to the 182 teacherfocused excerpts across the unit. As seen in the word cloud in Figure 2 above, there were two other areas of interest that appeared within the data. "Explicit Engineering Language", language that was either engineeringspecific (e.g., engineer, prototype, or criteria), or language that was specific to the curriculum and used in an engineering context (e.g., plan, try, or test) was noted with 59 separate excerpts coded as using engineering language. The other area of interest was "Connections to Curriculum" with 80 distinct excerpts. Excerpts were coded as "Connections to Curriculum" when prior lessons or concepts learned within those lessons were referenced either by the teacher or students.

\section{Engineering Design Process}

When looking more closely at the types of engineering and engineering design experiences, the progression follows the intended engineering design process as designed for this curriculum and seen in Figure 3. The progression is driven by the curriculum and mainly forwarded by the teacher, with the Define stage occurring in the introductory lesson and tapering as the classroom comes to a well-defined consensus on what the problem is, followed by multiple lessons where learning necessary background to solve the problem is the focus. Planning and building their basket design is found in the Plan and Try stages in Lesson 4B, while the Test and Decide stages occur in Lesson 5B in the curriculum. The students test their baskets with wet and dry rocks and decide whether their design meets the client's needs. A breakdown of the code counts for the different stages of the engineering design process that were seen within this unit can be found in Figure 3. 


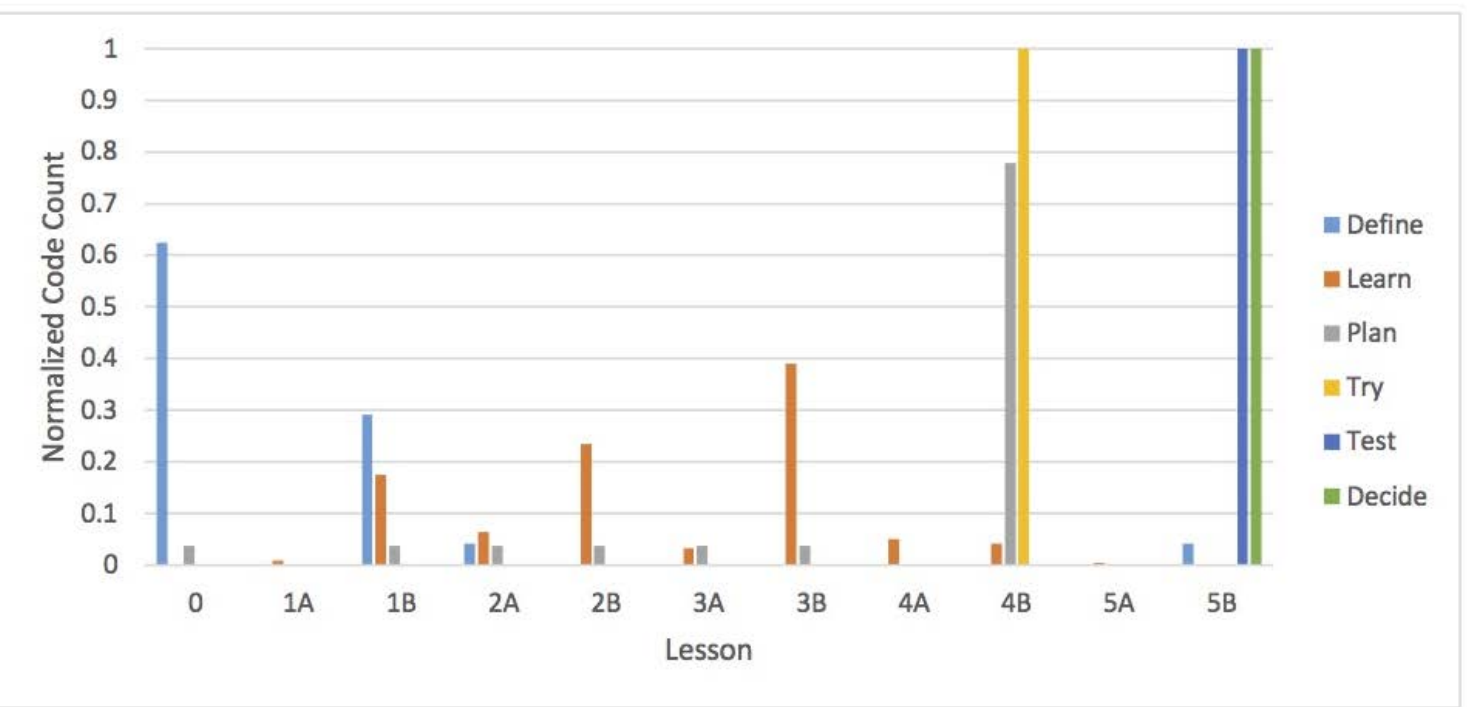

Figure 3. Normalized code count for Engineering Design Process steps across curriculum

Overall, the classrooms followed the expected engineering design process as it was designed to be implemented. However, engineering design is not a unidirectional procedure to be strictly adhered to, and while there is a definite progression through the process, there was evidence of kindergarten students engaging in design as an iterative process as seen in Figure 3 above. Aspects of defining the problem, learning about the problem and planning for solutions were seen to occur across multiple lessons throughout the curriculum. There were aspects related to Planning that occurred before the intended planning-focused lesson (4B) and were often prompted by students using the problem scenario set up in the beginning as a context for generating and discussing potential solutions related to this problem. One place where this occurred can be seen in the following teacher-initiated example, when the teacher was wrapping up the first lesson by asking students to relate their learning about paper back to the problem context and start to thinking about possible solutions:

Teacher: If we were making a basket, what would you want to make a basket out of? What paper would you choose?

Student: The see-through one

Teacher: Why would you choose this?

Student: Because it can get wet. C3, L1B

Students were able to explore a variety of STEM subject matter through this project. The other common place where this more iterative nature of engineering and design was seen was with those instances coded as part of the Learn phase of the Engineering Design Process. While there is a focus on the Learn phase within lessons 1, 2, and 3 in the curriculum, analysis revealed that there was evidence of the Learn phase seen in varying degrees across the lessons. When looking at little more closely at who was initiating and engaging in this learning, Figure 4 presents the breakdown of student and teacher talk and response across the "Learn" stage codes. 


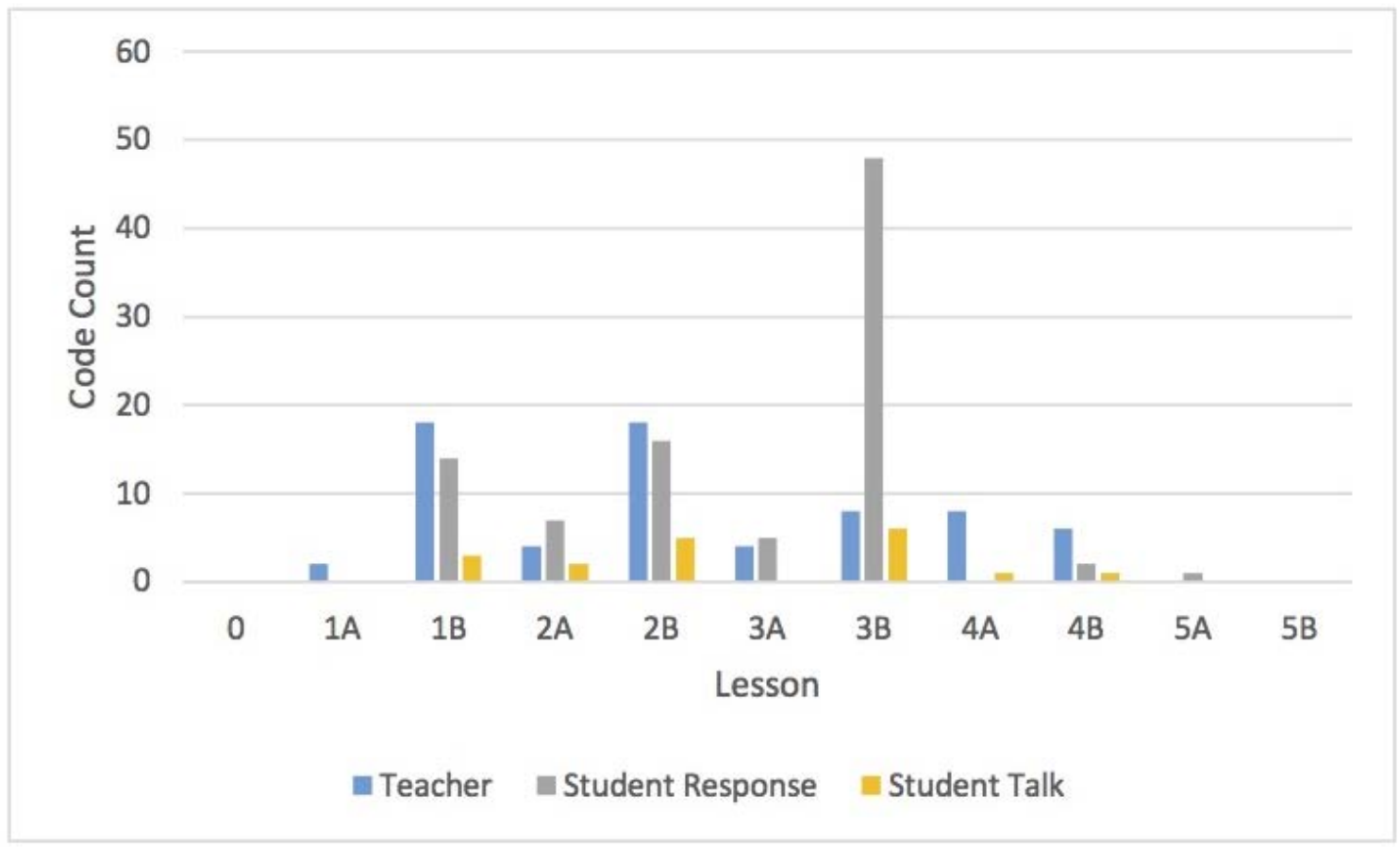

Figure 4. Instances coded as being directly a part of the "Learn" stage of the EDP

Fifteen percent, or seventeen out of 110 total student interactions, were coded as "Student Talk". Students need the guidance and prompting of the teacher to help them through the process of learning the background behind their engineering design project, scaffolding the lessons and encouraging students to share their findings.

As students explored the STEM lessons and learned more about the background information required to complete the design project, the following excerpt presents an example of a student developing experiments that could be used to learn more about the materials.

Student: Because I want to see, I want to do both and see which one is better

Teacher: Oh, so you want to do both pieces of paper to see which one works best? Why?

Student: Because so I could give the basket one of the papers.

Teacher: So you're seeing which paper would be the best for the basket.

Student: So I'm doing both. C3, L2B

Another theme that emerged related to engineering design was that even though the Kindergarten students were eager to jump into planning and building their basket designs they were able to keep a focus on the larger problem and working through the Engineering Design Process over many days. Additionally, both the teachers and students were seen using the engineering design process as a thread that connected the pieces of the curriculum. All of the teachers followed the curriculum as it was written and typically at the start of each lesson they would note where in the Engineering Design Process the class would focus for that day's lesson. The following example occurred at the start of the third STEM lesson:

Teacher: And we are right now in the process of....

Student: Learn!

Teacher: Learning, that's right! $C 1, L 3 B$

Teacher: So we're still on the Learn part, you're learning about how to weave to make your basket. C3, $L A A$

Furthermore, in the classroom where the Engineering Design Process was consistently and prominently displayed, the following examples showed students commenting on where they were and where they would be going in the design process.

Student: And you need to define it! Don't forget to define! C1, LO

Student: We're still on learning, are we on learning? C1, L1B

Student: Can we do plan? C1, LAB 
In all of these examples, the students were sharing their ideas after the teacher had introduced the goals of lesson and then directed their attention back to the engineering design process, but before the teacher explicitly identified where they were in the process.

\title{
Teacher \& Student Interaction
}

When considering the types of interactions seen throughout the unit, there were more student-focused excerpts, 265, compared to the 182 teacher-focused excerpts. Of the 182 teacher-focused excerpts, 148 were coded as "Teacher Talk" where the focus of the teacher's interaction is to guide the lesson by initiating conversation or providing knowledge. The remainder were often coded as "Teacher Action", 32 excerpts, where the teacher was primarily showing students how to do something or helping students to engage in a physical activity or "Teacher Response", 2 excerpts, where the teacher was primarily providing information or a response to students' prompts. With respect to the 265 student-focused excerpts, 144 were coded as "Student Response" where students were primarily responding to prompts from the teacher with information related to the project (e.g. "What are we designing?" "Baskets!" C1, L1B), 46 were coded as "Student Talk" where students were supplying information or inciting an engagement with the teacher or other classmates without outside prompting, and 75 were coded as "Student Action" where students were primarily focused on physical actions.

\section{Conceptions of Engineers and Engineering}

Another pattern that was seen during the analysis of the engineering experiences was that throughout this curriculum, students were building their understanding of the work of scientists and engineers, including beginning to identify themselves as being or being like engineers and scientists. Many of these instances were seen when the teachers facilitated this belief by helping students to prepare: "Now we are going to think like engineers, put on your invisible engineer thinking hats" $\mathrm{C} 3, \mathrm{LO}$. There were also instances where students are the ones to recall their role as scientists and engineers during future lessons with minimal prompting:

\author{
Student: We're gonna be like a scientist! \\ Teacher: We are, we're going to be like engineers. $C 1, L 3 B$ \\ Teacher: "This bridge must have been created by an engineer," explained Pedro \\ Student: That's what we are! C1, L5A
}

Both of these examples were unprompted and provided by female students. These unprompted student responses, taking on STEM self-conceptions, help to facilitate students' beliefs that one of their future selves could be as an engineer or other STEM professional. Students are eager to take on these STEM roles as they move through the curriculum.

Teacher: It's an engineering kids story book, written by...
Student: We're going to be engineers? C1, L5 A
Student: Can we do another experiment? C3, L2B

\section{Explicit Engineering Language}

Explicit engineering language, language that is either uncommon for kindergarten students to use (e.g. engineer, prototype, criteria, etc.) or that is specific to the EDP and used in that sense (e.g. plan, try, test, etc.) was coded when it was seen in the curriculum. The most common occurrence for explicit engineering language was at the beginning and end of the lessons, when the teacher was reminding students of the context or connecting what they had learned to the engineering design context. Students also used explicit engineering language, but not as often as teachers did as seen in Figure 5.

Explicit engineering language was often used when discussing or describing the engineering design process. Approximately half of the excerpts coded as explicit engineering language were also coded with "Engineering Design Process", meaning they occurred when directly discussing the engineering design process. Some instances of explicit language use reminded students of where they were and what they needed to do for the engineering design project, "Where's your plan, I need to see your plan before you come up to me" C1, LAB. 


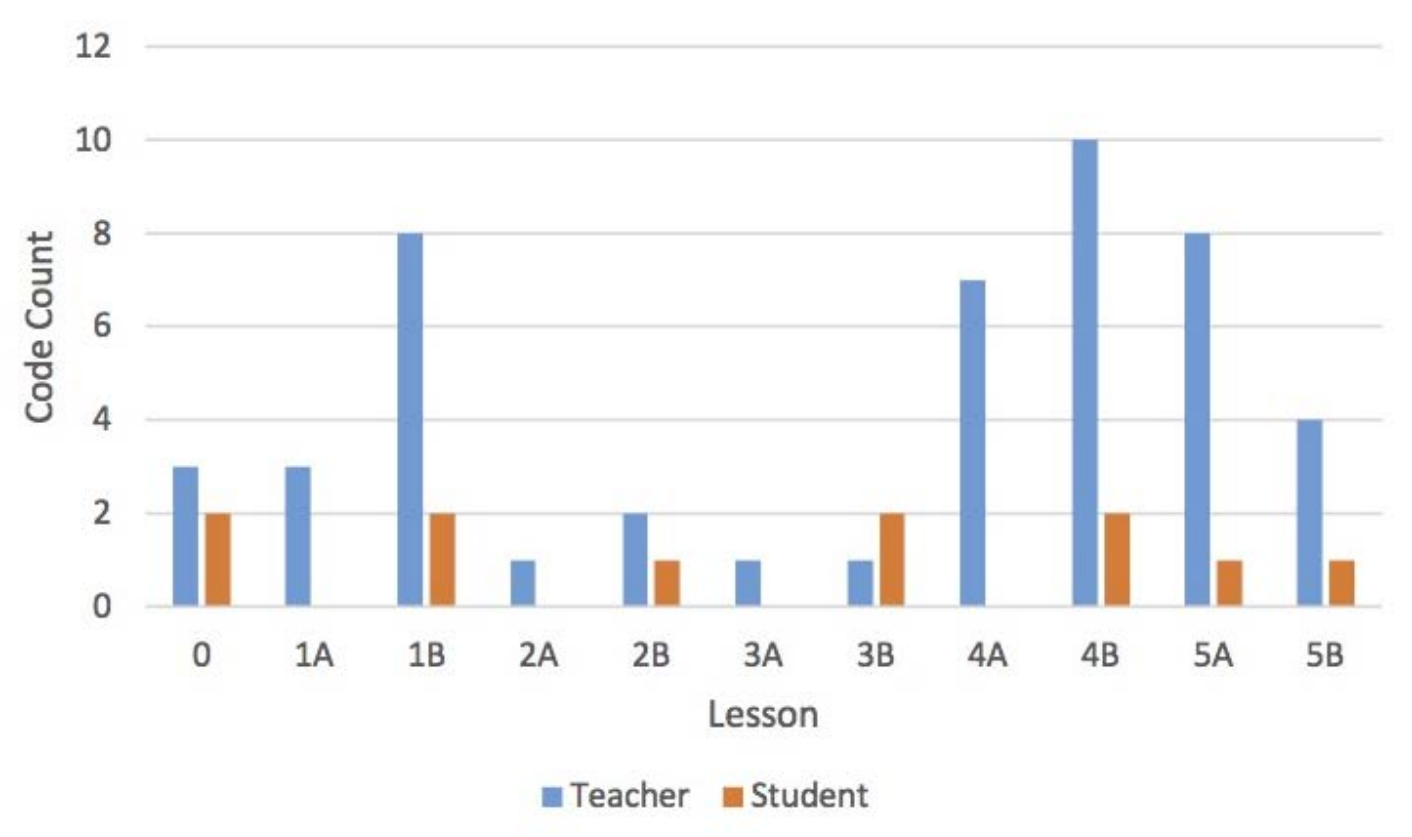

Figure 5. Instances coded as using curriculum-specific engineering language

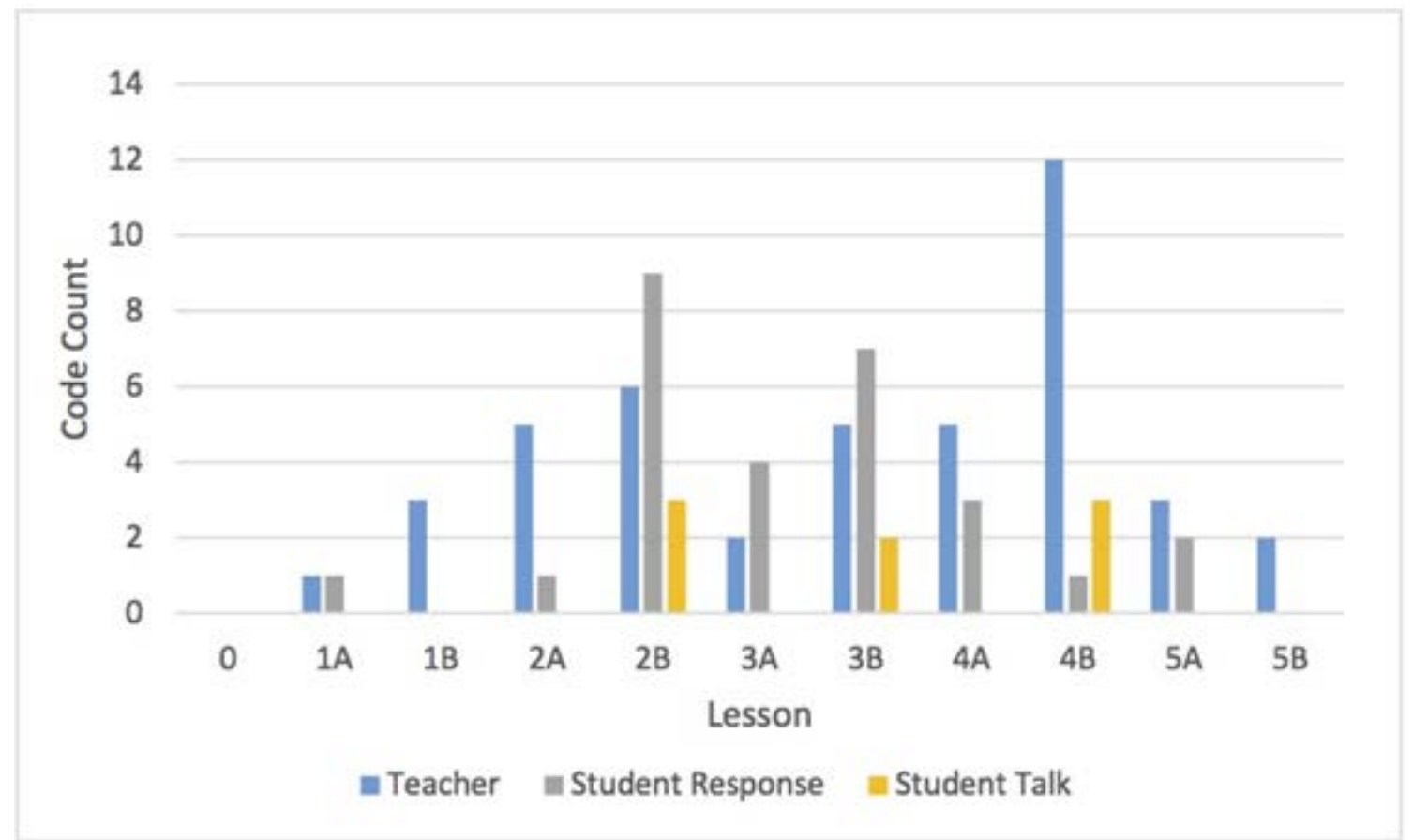

Figure 6. Instances where earlier lessons from the unit were recalled during later lessons

\section{Connections to Curriculum}

Teachers and students connected lessons across the curriculum to their design projects as seen in Figure 6. The integrated curriculum was designed so that students would be introduced to an engineering design problem, then learn what they needed to know to solve the problem through books and STEM lessons, and finally complete the engineering design project using the knowledge they had learned to help the client. In order to build upon each lesson, referring back to and transferring knowledge across the different pieces of the curriculum is necessary.

Twenty-two percent of the student-focused excerpts (8 of 36) were coded as "Student Talk", where students connected back to aspects of the curriculum in an unprompted manner. Students were able to make their own connections back to the books they had read, the experiments they had done, and to the context for the engineering design project. Connections to the curriculum often connected to a book that was read in preparation for a STEM lesson. 
Teacher: Earlier today we read Pattern Fish and we learned about patterns, right? Why did we learn about patterns? Raise your hand if you want to tell us why we learned about patterns.

Student: Patterns on our baskets. C1, LAB

Connections back to the curriculum also occurred when teachers and students were remembering where they were and what experiments they had done.

Teacher: We have talked about five different papers. We have talked about construction paper, we have talked about regular copy paper.

Student 1: No, I don't remember doing construction paper.

Student 2: I do.

Teacher: I think on the very first day we each had little squares and you had to feel the difference between them. You are right we haven't talked a whole lot about the construction paper but it's going to come in handy today. So construction paper, copy paper, oh, our favorite! Our favorite!

Student: Wax!

Teacher: Wax paper with that wax coating, we have tissue paper, we have paper towels, our five different papers. These are all papers you can find at your house if you looked really hard and Max and Lola want us to use some paper you can find at home, so this is some of the paper that you can find at home. C2, L3B

Connections across the lessons was also seen in un-prompted, or student-initiated instances when students would make their own connections between the subject-specific activities they conducted and the engineering design problem. In this example, the teacher had finished reading the second part of the book, I Get Wet by Vikki Cobb which is about the properties of water and was asking the students about what they learned from the book to move towards summarizing the text and a student replied, "I know what, which kind of paper to use!" C2, L3A. As expected, more connections were seen in the later lessons as students created a plan for solving the engineering problem using the knowledge from prior lessons. Some additional connections occurred as students talked about their plans and designs, however while many students described why they used specific materials they did not directly attribute their reasoning to the lesson or content where they learned the material properties, so these instances were not coded as directly connecting back to the curriculum.

\section{CONCLUSIONS}

As we looked at the implementation of an engineering design-based STEM integration unit in three Kindergarten classrooms, the goal of this exploratory, descriptive study was to gain a better understanding of how engineering can and should be integrated into early childhood classrooms. As engineering continues to expand into classrooms and contexts with young students, the question of what developmentally-appropriate engineering is and what does it look like for the teacher and student in classroom practice continues to be asked. Based on the results of this study, the authors assert that developmentally-appropriate engineering can: 1) incorporate multiple aspects of engineering and engineering design, 2) be scaffolded by the teacher to promote student talk and action, 3 ) include interdisciplinary content and connections, and 4) take place over an extended period of time, especially when using a visual representation of the engineering design process as an organizing tool and place marker.

Throughout the unit, the teachers and students were seen engaging with engineering and engineering design across the different lessons in an iterative manner, especially with defining the problem, learning about and planning for their design solutions that is more realistic of engineering. While this was largely teacher driven, these results suggest that kindergarten students are able to engage in problems that have multiple layers and require learning and revisiting ideas and possible solutions, which is an important aspect of engineering design and solving engineering problems (Tank et al., 2018; Lachapelle and Cunningham, 2014). This learning and revisiting of ideas and solutions was especially evident within the Learn phase of the EDP. Even though the curriculum was designed to have students learn the relevant background knowledge and revisit this knowledge in the context of students' ideas across multiple lessons, it was unclear how this would translate into practice and how much of an emphasis it would be given by the teachers and students. It was therefore encouraging to see knowledge building related to the problem and possible solutions across multiple lessons. 
Additionally, kindergarten students were not only engaging with the engineering activities, but they were also seen building their understanding of scientists and engineers as well as developing a better understanding of the work that engineers do (Adams et al., 2011). While this was commonly seen following teacher prompting or scaffolding, there was also evidence of student-initiated instances of building their own self-conceptions as engineers and scientists.

When looking at the teacher and student talk that occurred during this unit, the use of engineering design-based STEM integration was seen to promote the practices of language skills as it encouraged frequent instances of student talk and student response alongside with student action. While there was evidence of a larger number of student-focused excerpts identified within engineering, the teacher-student interactions within these lessons were found to be important for scaffolding and modeling of appropriate engineering language and practices which is similar to what has been recommended within the early engineering literature (Lippard et al., 2017).

Additionally, when looking at the enactment of engineering design-based STEM integration, this study suggests that engineering design provides a space and context not only for teachers to integrate and make connections across content areas, but also for students to make their own connections across disciplines. This was evident by the large number of excerpts that were dedicated to building background knowledge within mathematics and science content, but also seen with the frequent identification of connections across the literacy and STEM lessons and to their design projects by both students and the teachers. This is important when thinking about models of STEM and engineering as those recommended models would ideally encourage and support both student-directed and teacher directed interdisciplinary learning and thinking. Furthermore, when thinking about the studentinitiated and interdisciplinary thinking, some students were able to independently make connections to the classroom lessons when designing their basket however many of the students needed more direct prompting from the teacher in order to make these connections.

Finally, these results suggest that kindergarten students are able to complete long-term, multi-part engineering design projects that include integrated STEM lessons and that students can have high levels of understanding and engagement as seen by high levels of project-focused student responses. However, teachers are needed to facilitate and guide, but not constrain students during an engineering design-based project. This was especially true in the classroom, where the teacher and students frequently referred to the visual representation of the engineering design process that was hanging in their classroom as an organizing tool and place marker for where they were and what their next steps would be in solving their problem. Additionally, while some students were able to move more independently at this age (e.g., two students created experiments to test the paper, some students were independently following and keeping track of the EDP, some students made connections to being engineers and the engineering project without teacher prompting), all students appeared to benefit from the guided engineering experience.

\section{IMPLICATIONS}

When looking at the emphasis that is being placed on STEM and engineering at all levels, it is important to have a deep understanding of what these constructs mean at the various levels and what can and should be expected of teachers and students when put into practice. However, this is difficult with the limited body of research within STEM and engineering at the early childhood level. As the field is working to understand STEM and engineering at this level, this study sheds light on how engineering design can be used to facilitate STEM integration and how this can be enacted in early childhood classrooms in developmentally appropriate ways. Gaining a better understanding of engineering design-based STEM integration has several implications or the field. Time and space within the curriculum is limited, so adding more content is a challenge. This study was focused on the engineering that was present in early childhood classrooms within this engineering design-based STEM integration model, and it did not explicitly examine the literacy component. However, there was evidence of student and teacher-initiated talk and connections between STEM and literacy which suggests the potential for using engineering design-based STEM integration as a context for student learning in areas outside of STEM. Therefore, if engineering design can be used to facilitate learning in other content areas, such as STEM or literacy there is a greater chance of meaningfully making its way into and staying in early childhood classrooms where the day and content is already tightly packed. This indicates that additional research is needed to further examine this connection and the extent to which an engineering design-based STEM integration model could be used for content learning in non-STEM areas like literacy. Furthermore, when thinking about the preparation of future teachers and support for current teachers, gaining a better understanding of what STEM and engineering look like in practice can help with teacher preparation and professional development efforts for teachers who have limited background, experience and confidence in teaching STEM and engineering. 


\section{ACKNOWLEDGEMENTS}

This work is supported by the National Science Foundation under grant numbers NSF DRL- 1543175 and NSF EEC-1442416. Any opinions, findings, and conclusions or recommendations conveyed in this study are those of the authors and do not necessarily reflect the views of the National Science Foundation.

\section{REFERENCES}

Adams, R., Evangelou, D., English, L., Figueiredo, A. D., Mousoulides, N., Pawley, A. L., ... and Wilson, D. M. (2011). Multiple perspectives on engaging future engineers. Journal of Engineering Education, 100(1), 48-88. https://doi.org/10.1002/j.2168-9830.2011.tb00004.x

Bairaktarova, D., Evangelou, D., Bagiati, A. and Brophy, S. (2011). Early engineering in young children's exploratory play with tangible materials. Children Youth and Environments, 21(2), 212-235.

Banilower, E. R., Smith, P. S., Weiss, I. R., Malzahn, K. M., Campbell, K. M., and Weis, A. M. (2013). Report of the 2012 National Survey of Science and Mathematics Education. Chapel Hill, NC: Horizon Research, Inc.

Brophy, S. P. and Evangelou, D. (2007). Precursors to engineering thinking. In Proceedings of the Annual Conference of the American Society of Engineering Education. Honolulu, HI.

Brophy, S., Klein, S., Portsmore, M. and Rodgers, C. (2008). Advancing Engineering Education in P-12 Classrooms. Journal of Engineering Education, 97(3), 369-387. https://doi.org/10.1002/j.21689830.2008.tb00985.x

Copple, C. and Bredekamp, S. (2009). Developmentally appropriate practice in early childhood programs serving children from birth through age 8. Washington, DC: National Association for the Education of Young Children.

Cunningham, C. M. and Lachapelle, C. P. (2014). Designing engineering experiences to engage all students. In S. Purzer, J. Strobel, and M. Cardella (Eds.), Engineering in pre-college settings: synthesizing research, policy, and practices (pp. 117-142). Lafayette: Purdue University Press.

Derry, S. J., Pea, R. D., Barron, B., Engle, R. A., Erickson, F., Goldman, R., ... and Sherin, B. L. (2010). Conducting video research in the learning sciences: Guidance on selection, analysis, technology, and ethics. The Journal of the Learning Sciences, 19(1), 3-53. https:// doi.org/10.1080/10508400903452884

Dym, C. L. (1999). Learning engineering: Design, languages, and experiences. Journal of Engineering Education, 88(2), 145-148. https://doi.org/10.1002/j.2168-9830.1999.tb00425.x

English, L. D. (2016). STEM education K-12: perspectives on integration. International Journal of STEM Education, 3(1), 3. https://doi.org/10.1186/s40594-016-0036-1

English, L. D. and King, D. T. (2015). STEM learning through engineering design: fourth-grade students' investigations in aerospace. International Journal of STEM Education, 2(1), 14. https://doi.org/10.1186/s40594015-0027-7

Fleiss, J. L. (1971). Measuring nominal scale agreement among many raters. Psychological Bulletin, 76(5), 378-382. https://doi.org/10.1037/h0031619

Grubbs, M. and Strimel, G. (2015) Engineering design: The great integrator. Joumal of STEM Teacher Education, 50(1), 77-90.

Kuhn, D. and Pearsall, S. (2000). Developmental origins of scientific thinking. Journal of cognition and Development, 1(1), 113-129. https://doi.org/10.1207/S15327647JCD0101N_11

Landis, J. R. and Koch, G. G. (1977). The measurement of observer agreement for categorical data. Biometrics, 33(1), 159-174. https://doi.org/10.2307/2529310

Lincoln, Y. S. and Guba, E. G. (1985). Naturalistic inquiry. CA, US: Sage Publications

Lippard, C. N., Lamm, M. H. and Riley, K. L. (2017). Engineering Thinking in Prekindergarten Children: A Systematic Literature Review. Journal of Engineering Education, 106(3), 454-474. https://doi.org/10.1002/jee.20174

Miles, M. B., Huberman, A. M. and Saldaña, J. (2014) Qualitative data analysis: A Methods Sourcebook. CA, US: Sage Publications.

Moore, T. J. and Tank, K. M. (2014). Chapter 13: Picture STEM. In C. Sneider (Ed.), The go-to guide for engineering curricula, preK-5!. Thousand Oaks, CA: Corwin Press.

Moore, T. J., Glancy, A. W., Tank, K. M., Kersten, J. A., Smith, K. A. and Stohlmann, M. S. (2014). A Framework for Quality K-12 Engineering Education: Research and Development. Journal of Pre-College Engineering Education Research (J-PEER), 4(1), Article 2. https:// doi.org/10.7771/2157-9288.1069

Moore, T. J., Stohlmann, M. S., Wang, H.-H., Tank, K. M., Glancy, A. W. and Roehrig, G. H. (2014). Implementation and integration of engineering in K-12 STEM education. In S. Purzer, J. Strobel and M. Cardella (Eds.), Engineering in precollege settings: Synthesizing Research, Policy, and Practices. Lafayette, IN: Purdue University Press. 
Moore, T. J., Tank, K. M., Glancy, A. W. and Kersten, J. A. (2015). NGSS and the Landscape of Engineering in K-12 State Science Standards. Journal of Research in Science Teaching, 52(3), $296-318$. https://doi.org/10.1002/tea.21199

National Academy of Engineering. (2008). NAE Grand Challenges for Engineering. Available at: http:/ / engineeringchallenges.org/ (Accessed 28 March 2018).

National Research Council. (2012). A framework for K-12 science education: Practices, crosscutting concepts, and core ideas. Washington, DC: The National Academies Press.

National Research Council. (2014). STEM integration in K-12 education: Status, prospects, and an agenda for research. Washington, DC: National Academies Press.

Randolph, J. J. (2005). Free-marginal multirater kappa: An alternative to Fleiss' fixed-marginal multirater kappa. Paper presented at the Joensun University Learning and Instruction Symposium 2005, Joensuu, Finland, October 14-15th, 2005. (ERIC Document Reproduction Service No. ED490661)

Tank, K. M., Moore, T. J., Dorie, B. L., Gajdzik, E., Sanger, M. T., Rynearson, A. M. and Mann, E. F. (2018). Engineering in early elementary classrooms through the integration of high-quality literature, design, and STEM+C content. In L. English and T. Moore, (Eds.), Early Engineering Learning (pp. 175-201). Singapore: Springer.

Tank, K. M., Moore, T. J., Gajdzik, E. A., Sanger, M. T., Rynearson, A. M., Dorie, B. L. and Mann, E. F. (2016, June). Designing Paper Baskets: A PictureSTEM Curriculum Module (P12 Resource Exchange). Presentation at the at the 2016 American Society of Engineering Education (ASEE) annual conference, New Orleans, LA. https://doi.org/10.18260/p.26705

Watkins, K., Spencer, J. and Hammer, D. (2014). Examining Young Students' Problem Scoping in Engineering Design. Journal of Pre-College Engineering Education Research, 4(1), $43-53$. https://doi.org/10.7771/\n10.7771/2157-9288.1082

Wendell, K. and Rogers, C. (2013). Engineering design-based science, science content performance, and science attitudes in elementary school. Journal of Engineering Education, 102(4), 513-540. https://doi.org/10.1002/jee.20026 